http://dx.doi.org/10.18675/1981-8106.vol25.n49.p253-267

\title{
Educação profissional integrada ao ensino médio no Paraná: limites e possibilidades EpiemP:Ip
}

\author{
Professional Education integrated to high school in the state of Paraná: limits \\ and possibilities PeihssP:lp
}

\section{Educación profesional integrada a la enseñanza media en Paraná: límites y posibilidades EpiemP:Ip}

\author{
Eliane Cleide da Silva Czernisz' \\ Marci Batistão" \\ 'Universidade Estadual de Londrina (UEL), Londrina, Paraná - Brasil. E-mail: elianecleide@gmail.com \\ "Universidade Estadual de Londrina (UEL), Londrina, Paraná - Brasil. E-mail: marci@uel.br
}

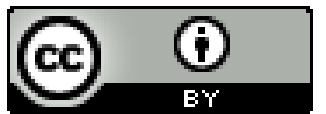

Educação: teoria e prática, Rio Claro, SP, Brasil - eISSN: 1981-8106

Está licenciada sob Licença Creative Common

\section{Resumo}

Este texto analisa a integração do ensino médio à educação profissional, desenvolvida pelo Estado do Paraná no período de 2003 a 2010. Os argumentos apresentados foram obtidos a partir de discussão bibliográfica e análise de documentos e legislação da educação, que fundamentam, também, as questões relativas ao sentido assumido pelo currículo para o processo de integração da educação profissional ao ensino médio no Paraná. A análise realizada permite observar que os percalços que se apresentaram durante tal processo indicam divisões e antagonismos que se encontram na base da organização da sociedade capitalista e, por isso mesmo, representam importante complexidade. Também, possibilita o entendimento da constante necessidade de reflexão acerca dos limites e possibilidades da educação profissional integrada ao ensino médio como uma questão imprescindível a um país que busca o desenvolvimento, mas que tem, fundamentalmente, o dever de pensar na melhoria das condições de vida dos trabalhadores, garantindo-lhes a formação profissional como direito social.

Palavras-chave: Política educacional; Educação profissional; Ensino médio. Currículo. 


\begin{abstract}
This text analyzes the integration of high school to professional education that was developed by the State of Parana during the period of 2003 to 2010. The arguments presented were obtained from a bibliographical discussion and an analysis of documents and the education legislation, which also provide the basis for the questions concerning the direction adopted by the curriculum for the integration process of professional education to high school in Paraná State. This analysis carried out permits the observation that obstacles presented during such a process indicate both divisions and antagonisms, which are found on the basis of the capitalist society and, for this reason, represent important complexity. It also enables the understanding of the constant need for reflection upon constraints and possibilities of professional education integrated to high school. This is a crucial matter to a country that seeks development, but which has the essential duty of considering the improvement of workers' life conditions, by ensuring their professional formation as a social right.
\end{abstract}

Keywords: Educational policy; Professional education; High school; Curriculum.

\title{
Resumen
}

Este texto analiza la integración de la enseñanza media a la educación profesional, desarrollada por el Estado de Paraná en el período de 2003 a 2010. Los argumentos presentados se obtuvieron a partir de discusión bibliográfica y análisis de documentos y legislación de la educación, que fundamentan, también, las cuestiones relativas al sentido asumido por el currículo para el proceso de integración de la educación profesional a la enseñanza medio en Paraná. El análisis realizado permite observar que los contratiempos que se presentaron durante tal proceso indican divisiones y antagonismos que se encuentran en la base de la organización de la sociedad capitalista y, por eso mismo, representan una importante complejidad. También posibilita el entendimiento de la constante necesidad de reflexión acerca de los límites y posibilidades de la educación profesional integrada a la enseñanza media como una cuestión imprescindible a un país que busca el desarrollo, pero que tiene, fundamentalmente, el deber de pensar en la mejoría de las condiciones de vida de los trabajadores, garantizándoles la formación profesional como derecho social.

Palabras clave: Política educacional; Educación profesional; Enseñanza media; Currículo.

\section{Introdução}

Educação: Teoria e Prática/ Rio Claro/ Vol. 25, n.49/ p. 253-267/ Mai-Ago. 2015. 
No Brasil, as políticas educacionais para a educação profissional média têm se caracterizado por propostas que buscam formar trabalhadores para atender à sociedade capitalista. Atualmente, diante da expansão das formas produtivas baseadas na acumulação flexível, conceito desenvolvido por Harvey (1994), em virtude da qual ocorre a flexibilização da produção, do mercado de trabalho e dos padrões de consumo, as propostas para a formação profissional têm acentuado o atendimento ao mercado de trabalho. Percebe-se que novas proposições são feitas para a profissionalização no ensino médio, em oposição à formação que privilegia o mercado, razão deste texto, que tem como objetivo discutir a proposta de educação profissional integrada ao ensino médio, desenvolvida pelo Estado do Paraná, a partir de discussão bibliográfica e análise de documentos. Trata-se de um dos estados da federação que iniciaram, no ano de 2003, a integração entre educação profissional e ensino médio. Esse fato nos permite questionar: qual o sentido do currículo nessa integração? Como ocorreu a integração da educação profissional ao ensino médio no Paraná? Quais as possibilidades e limites da proposta? Tais questões, a nosso ver, são necessárias à reflexão de educadores, instituições e redes de ensino.

Consideramos que a referida integração implica o redimensionamento do projeto pedagógico para a profissionalização, o desenvolvimento de ações abrangendo a formação de adolescentes e jovens, além de requerer, também, discussão e construção de um projeto educativo dentro de uma sociedade que poderá buscar uma saída para a profissionalização, prioritariamente, comprometida com o desenvolvimento daqueles que irão atuar no mundo do trabalho.

\section{Educação profissional integrada ao ensino médio: o sentido do currículo}

No cenário brasileiro, desde meados da década de 1980 e de 1990, passou a ocorrer uma mobilização com vistas a uma educação básica unitária, como apontaram Frigotto, Ciavatta e Ramos (2005), pela qual o princípio educativo do trabalho no ensino médio permitiria sua ressignificação.

As afirmações dos autores podem ser constatadas também em Machado (1991), permitindo verificar que a discussão a respeito da politecnia no ensino médio já estava em pauta no seminário Propostas para o ensino médio na nova $L D B$, desenvolvido pelo MEC em 1989, antes da aprovação da Lei de Diretrizes e Bases da Educação Nacional em vigor. Naquele momento, questionava-se se a proposta de escola unitária poderia ser aplicada no segundo grau e buscava-se, com a educação politécnica, a formação omnilateral.

Nesse seminário, foi problematizada a necessidade de reorganização escolar e foram considerados como dificuldades tanto os suportes de infraestrutura quanto a formação de docentes para encaminhar a proposta. Além dessas questões, também foi discutida a necessidade de uma estrutura unitária do ensino, o que implicava repensar o currículo, conforme afirmado por Machado (1991, p. 60): 
O currículo na perspectiva do ensino politécnico pressupõe a articulação dos conteúdos sob novos contornos que envolvem, basicamente, três dimensões: a primeira, os objetivos do trabalho humano; a segunda, os instrumentos, as máquinas e os mecanismos; a terceira, as relações da organização social e do trabalho.

O sentido da formação politécnica, discutida por Machado (1989, p. 128), tem por base a concepção de educação em Marx, que “[...] parte da atividade material produtiva, do trabalho, pois esta constitui a primeira e essencial instância educativa do homem. Pelo trabalho, o homem aprende a dominar a natureza, aprendendo todo tipo de conhecimento que se faça necessário a esta tarefa".

Manacorda (1991) complementa essa análise, comentando o processo de alienação que se dá na produção, empobrecendo a atividade humana, como explicitado por Marx e Engels (2004, p. 27):

\begin{abstract}
A força de trabalho em ação, o trabalho mesmo, é, portanto, a atividade vital peculiar ao operário, seu modo peculiar de manifestar a vida. E é esta atividade vital que ele vende a um terceiro para assegurar-se dos meios de subsistência necessários. Sua atividade vital não lhe é, pois, senão um meio de poder existir. Trabalha para viver. Para ele próprio, o trabalho não faz parte de sua vida; é antes um sacrifício de sua vida. É uma mercadoria que adjudicou a um terceiro. Eis porque o produto de sua atividade não é também o objetivo de sua atividade.
\end{abstract}

Manacorda ressalta a necessidade de superar tal alienação e diz: “[...] Para Marx, ao contrário, trata-se de superar a alienação concreta, a separação entre trabalho e a manifestação de si mesmo, produzida historicamente pela divisão do trabalho" (MANACORDA, 1991, p. 24). Percebe-se que o trabalho ocupa o cerne da proposta educativa de Marx, que resultará no desenvolvimento da omnilateralidade compreendida como:

[...] a chegada histórica do homem a uma totalidade de capacidades produtivas e, ao mesmo tempo, a uma totalidade de capacidades de consumo e prazeres, em que se deve considerar sobretudo o gozo daqueles bens espirituais, além dos materiais, e dos quais o trabalhador tem estado excluído em consequência da divisão do trabalho (MANACORDA, 1991, p. 81).

Manacorda reforça que, para que a omnilateralidade seja desenvolvida, seria preciso reunificar as "[...] estruturas da ciência com as da produção" (MANACORDA, 1991, p. 85). 
Esse aspecto incide no desenvolvimento do currículo e de um novo tipo de escola. Como foi analisado por Machado (1989, p. 88-89)

\begin{abstract}
Marx e Engels concebiam as atividades de trabalho e educação como integrantes de um único processo, com articulação entre teoria e prática. Pela chamada educação politécnica, através da qual seriam transmitidos os princípios gerais e de caráter científico de todo o processo de produção, além de uma iniciação no manejo das ferramentas elementares das diversas profissões, acreditavam que seriam atingidos três objetivos: a intensificação da produção social, a produção de homens plenamente desenvolvidos e a obtenção de poderosos meios de transformação da sociedade capitalista.
\end{abstract}

Buscava-se, então, por uma nova proposta de educação, a superação de uma condição de classe pela suplantação da dicotomia que prevalecia no trabalho. E, de acordo com Machado (1989, p. 95), era necessário superar a divisão entre trabalho intelectual e trabalho manual visando ao "[...] desenvolvimento multilateral dos indivíduos". Esse é o eixo que fundamenta as propostas lançadas no tempo presente: a formação omnilateral de adolescentes e jovens, mediante a integração entre os conhecimentos da base geral e os da base profissional.

Essa proposta fica clara, também, na análise desenvolvida por Saviani (2007, p. 160), ao discutir a relação trabalho e educação na escola elementar, a escola de ensino fundamental e médio. Afirma ele que "[...] o trabalho orienta e determina o caráter do currículo escolar". Por isso o autor sugere que, se no ensino fundamental são trabalhados conteúdos que permitem ao aluno aprender "[..] a ler, escrever e contar, e dominar os rudimentos das ciências naturais e das ciências sociais [...]", no ensino médio, é preciso "[...] explicitar como o conhecimento (objeto específico do processo de ensino, isto é, como a ciência, potência espiritual, se converte em potência material no processo de produção". Há a necessidade de possibilitar aos alunos o conhecimento numa articulação entre saber teórico e saber prático para que compreendam o mundo da produção.

Apesar de tal defesa, os anos de 1990 foram, novamente, de investimentos na formação profissional com a finalidade de atender às demandas de desenvolvimento econômico. No texto da LDBEN 9394/96, a educação profissional figura dissociada da educação básica, apesar de conter no parágrafo relativo à educação média alguns indícios da educação politécnica, como comentou Saviani (1997). Mesmo com a sutileza da menção feita à educação politécnica, na LDBEN 9394/96, o ensino médio de conteúdo geral figura separado da profissionalização, explicitando a conotação utilitarista da profissionalização na letra da Lei.

A partir do Decreto 2208/97, ocorre a regulamentação da educação profissional e, conforme o instrumento em questão, esta poderia ser desenvolvida de forma básica, técnica ou tecnológica. Os níveis distintos de formação resultaram numa profissionalização também diferenciada, inclusive pelo fato de alguns cursos ficarem sob responsabilidade de instituições 
de ensino normatizadas pelo Ministério da Educação e outros terem sido desenvolvidos pelo Sistema $S^{1}$ ou por parceiros vinculados ao Ministério do Trabalho e Emprego, como mencionado por Frigotto, Ciavatta e Ramos (2005), desde uma formação básica e rápida, caracterizada mais como treinamento para inserção pontual no mercado de trabalho, até uma formação baseada em um projeto mais elaborado.

A separação entre educação básica e educação profissional na LDBEN, assim como sua diferenciação em níveis, proporcionou a especulação da iniciativa privada. A educação profissional deixou de ser responsabilidade do Estado, passando a ser, concretamente, o que já era desejo de muitos representantes de empresas e do capital: um negócio, possibilitado pelo treinamento de parte da população que objetivava sua inserção no mercado de trabalho ou que iria compor o grande número de trabalhadores de reserva para as barganhas salariais.

A possibilidade de integração entre ensino médio e educação profissional se concretiza com o Decreto 5154/2004 e revogação do Decreto 2208/97, a qual, como comentado por Frigotto, Ciavatta e Ramos (2005), foi fruto de embates em que educadores brasileiros buscavam uma formação unitária por meio da integração entre ensino médio e profissional, vinculando a educação à prática social do trabalho, e tendo, como eixo organizador da formação, o trabalho como princípio educativo.

As considerações tecidas até aqui permitem notar que as propostas de profissionalização desenvolvidas no Brasil têm atendido necessidades do mercado de trabalho, movidas pelo desenvolvimento econômico. A mudança da concepção de formação e de um novo currículo são questões que exigem compreender os fundamentos que orientam e o sentido assumido pela formação. Esta seria a direção que permitiria integrar a educação profissional ao ensino médio como pode ser verificado na proposta de integração da educação profissional ao ensino médio no Paraná.

\subsection{A integração da educação profissional ao ensino médio no Paraná}

A Secretaria Estadual de Educação do Paraná iniciou a integração da educação profissional ao ensino médio em 2003, por meio de uma experiência encaminhada pelo MEC, em três estados brasileiros: Santa Catarina, Espírito Santo e Paraná. No governo do então Presidente da República Luís Inácio Lula da Silva, no mesmo ano, ocorreu a organização de seminários sobre a educação profissional, como comentaram Ferreira e Garcia (2005). No Paraná, a proposta de integração foi iniciada no governo de Roberto Requião, e, desenvolvida entre os anos de 2003-2010, contrapôs-se ao encaminhamento dado à educação profissional adotado no governo de Jaime Lerner nos anos de 1995-2002. Lerner, naquele período, desenvolveu uma política de retirada da educação profissional das escolas públicas paranaenses, deixando-a apenas em alguns centros estaduais em que era desenvolvida

\footnotetext{
${ }^{1}$ O Sistema S, conforme descrição de Manfredi (2002), apresenta-se como uma rede de educação profissional que representa o empresariado. Tem sua organização e gestão a partir de sindicatos e desenvolve ações paraestatais. São componentes do Sistema S: SENAI; SENAC; SENAR; SENAT; SESI.
} 
mediada por ações que indicavam a privatização, como o gerenciamento da educação profissional por uma agência social autônoma localizada fora da Secretaria Estadual de Educação: a Agência para o Desenvolvimento da Educação Profissional - PARANATEC.

A alteração, ocorrida no governo de Roberto Requião, foi clara no sentido de promover a retomada da educação profissional, assim como sua integração ao ensino médio tratando-a como política pública. Para tanto, destaca-se a criação, no ano de $2003^{2}$, do Departamento de Educação Profissional na Secretaria Estadual de Educação do Paraná, demarcando a educação profissional como política pública, como comentou Angeli (2008). Segundo análises da Secretaria Estadual de Educação do Paraná (PARANÁ, 2005), no início do governo Requião, havia no Estado apenas 13 cursos da área agropecuária, 14 cursos de formação de professores. Da área industrial, havia apenas 04 cursos ofertados, e 20 com foco na área de serviços (PARANÁ, 2005). Esse número é resultado da política de cessação da educação profissional no governo Lerner. Os números de cursos e de matriculados se expandem. Verifica-se, a partir dos dados apresentados por Griebeler (2013, p. 115), que o número de matriculados na educação profissional no ano de 2003 era de 18.290, sendo que, em 2005, os registros do MEC/INEP apontavam 48.030 matriculados, ficando clara a ampliação do número de alunos. Com relação à quantidade de cursos, Saldanha e Oliveira (2012, p. 52) apontam a expansão ocorrida no governo Requião, sendo a oferta “[...] até 2008, de 365 cursos na modalidade subsequente e 309 de ensino médio integrado - no início de 2003 restavam apenas 191 cursos profissionais".

Nas discussões de Ferreira e Garcia (2005), percebe-se o tratamento da educação profissional como política pública, cujo objetivo era superar as desigualdades sociais pela promoção da educação profissional integrada ao ensino médio, visando a atender toda a demanda existente. Ferreira e Garcia esclarecem que a exposição de motivos que acompanhou a proposição do Decreto 5154/2004 era de que tanto a LDB 9394/96 quanto o Decreto 2208/97 estavam descumprindo o princípio legal de “[...] integração da educação profissional com o processo produtivo, com a produção de conhecimento e com o desenvolvimento científico-tecnológico [...]” (FERREIRA; GARCIA; 2005, p. 151).

Na visão de Ferreira e Garcia (2005), um dos motivos que levaram a uma série de discussões preparatórias para a reestruturação curricular foi a avaliação de que a educação profissional havia sido atingida pelas políticas educacionais encaminhadas no governo de Fernando Henrique Cardoso que, a partir da aprovação da LDB 9394/96 e do Decreto 2208/97, naquele período, teve alteradas sua concepção, organização, proposta de formação e modo de oferta com a separação entre educação profissional e ensino médio. Para as autoras, integrar a educação profissional ao ensino médio "[...] pressupõe a formação de pessoas que compreendam a realidade e que possam atuar como profissionais" (FERREIRA; GARCIA, 2005, p. 164).

\footnotetext{
${ }^{2}$ Ocorreu, segundo Griebeler (2013), ampla reorganização departamental na Secretaria de Educação do Paraná, que contemplou os níveis e modalidades de ensino.
} 
As proposições da Secretaria Estadual de Educação para a formação integrada da educação profissional ao ensino médio foram apresentadas no Documento Fundamentos Políticos e Pedagógicos da Educação Profissional no Paraná (2005), no qual focaliza-se a integração entre educação profissional e educação básica e enfatiza-se a dimensão teóricometodológica da referida integração.

É destacado no documento supracitado que, no período de 2003 e 2004, foi feita uma série de estudos e preparo para organização de novos cursos. De acordo com o documento, a elaboração das propostas de cursos teve a participação tanto da equipe do departamento de educação profissional quanto de membros dos Núcleos Regionais de Ensino no Paraná. É ressaltado nele, também, que as propostas de cursos novos tramitaram e foram aprovadas pelo Conselho Estadual de Educação, no ano de 2003. Além disso, reforça-se que a expansão de cursos também foi aprovada em 2003, para ser desenvolvida em 2004. De acordo com o documento, tais medidas "[...] são consideradas importantes para o processo de consolidação da política de retomada da oferta da Educação Profissional pela Rede Pública Estadual" (PARANÁ, 2005, p. 10).

Observa-se, no documento, que a retomada da educação profissional se desenvolve como meta do plano de governo como podemos verificar no trecho abaixo:

\begin{abstract}
A educação profissional é parte integrante do Plano de Governo a ser desenvolvido pelo Estado do Paraná, bem como do projeto de educação definido para a gestão 2003/2006 que dele se deriva e que está fundamentada nos princípios de gestão democrática. Esses princípios consideram a educação como direito do cidadão, a universalização do ensino, a escola pública, gratuita e de qualidade, o combate ao analfabetismo, o apoio à diversidade cultural, a organização coletiva do trabalho escolar (PARANÁ, 2005, p. 33).
\end{abstract}

Em síntese, a proposta que visa a integrar a educação profissional ao ensino médio concebe o trabalho como princípio educativo. Nela, o sentido de um currículo integrado é atribuído, primeiramente, à possibilidade de uma formação omnilateral do estudante, o que não é exclusivo para a etapa da educação profissional e ensino médio. Tal proposta tem o potencial de desenvolver e integrar as dimensões que estruturam a prática social e que são fundamentais para a vida: o trabalho, a ciência e a cultura. De acordo com Ramos (2008, p.3):

Compreender a relação indissociável entre trabalho, ciência e cultura significa compreender o trabalho como princípio educativo, o que não se confunde com o "aprender fazendo", nem é sinônimo de formar para o exercício do trabalho. Considerar o trabalho como princípio educativo equivale dizer que o ser humano é produtor de sua realidade e, por isto, se apropria dela e pode transformá-la. [...] o trabalho é a primeira mediação entre o homem e a realidade material e social. 
É oportuno mencionar o ranço histórico, indicado por essa autora, que sempre marcou o ensino médio, a sua centralidade no mercado de trabalho de forma imediata, "[...] em que a relação econômica vai se tornando fundamento da profissionalização" (RAMOS, 2008, p.5) sem a devida consideração a aspectos mais amplos, contextuais. $\mathrm{O}$ sentido de um currículo integrado busca romper com esse vício. Frigotto, Ciavatta e Ramos (2005, p.35) assinalam que o ensino médio deveria ter como objetivo proporcionar aos alunos "[...] o domínio dos fundamentos das técnicas diversificadas utilizadas na produção, e não o mero adestramento em técnicas produtivas. Não se deveria, então, propor que o ensino médio formasse técnicos especializados, mas sim politécnicos". Esta é uma proposta de superação de modelos educativos que ora buscam formar para o trabalho, ora pretendem formar para a cidadania.

É neste espírito que se ambienta e propõe um currículo integrado, que, ao contrário de juntar duas formações distintas - ensino médio e educação profissional - pela divisão promovida pela LDBEN 9394/96, que os integre, de forma articulada, procurando atingir a função social da escola pretendida, uma educação em que "[...] todos tenham acesso aos conhecimentos, à cultura e às mediações necessárias para trabalhar e para produzir a existência e a riqueza social" (RAMOS, 2008, p.2).

Para encaminhar tal proposta, conforme defenderam Ferreira e Garcia (2005), foi necessário construir novos espaços frente às práticas oriundas da educação profisssional desenvolvidas pelo governo anterior. As autoras destacam que foi elaborada uma proposta de reestruturação curricular, tendo o trabalho como princípio educativo. Iniciou-se a formação continuada de professores e processou-se a reestruturação também de escolas da rede. Observam que as discussões que envolviam o currículo foram ponto central do trabalho nesse período, e desenvolveram-se fundamentadas

[...] nos princípios pedagógicos do trabalho, da cultura, da ciência e da tecnologia, os quais devem estar permanentemente presentes nas atividades de ensino/aprendizagem planejadas e desenvolvidas na escola, discutida e assumida pelo coletivo de seus profissionais e devidamente sistematizada em seu Projeto Pedagógico (FERREIRA, GARCIA, 2005, p. 163).

É oportuno destacar, no entanto, que o percurso pretendido para a materialização do processo de integração deparou-se com alguns obstáculos, que precisam ser sinalizados a fim de se demonstrar a complexidade que o tema encerra.

Sobre a questão da reestruturação curricular, por exemplo, convém assinalar que as escolas profissionais precisam lidar com diretrizes diferentes. No caso do Paraná, além das diretrizes nacionais para a Educação Básica e Profissional, é necessário, também, levar em conta a diretriz estadual, que, somadas às políticas de apoio à implementação curricular como o livro didático, formação continuada, entre outras -, reservam ao processo alguns 
complicadores, até porque tais diretrizes e políticas não necessariamente guardam coerência entre si, fator que traz dificuldades para se promover a integração.

Ainda a respeito da formação continuada dos professores e demais profissionais, embora tenha sido alvo durante o processo de integração, encerra dificuldades por fatores de natureza administrativa, que, genericamente, podem ser relacionadas à questão dos planos de carreira dos profissionais, que, infelizmente, não contribuem para um trabalho integrado.

\subsection{Possibilidades e limites da proposta de integração}

Analisar possibilidades e limites da implementação do currículo integrado passa por algumas questões que aqui precisam ser pontuadas. A primeira delas é considerar que as alterações curriculares que visam à formação, tendo o trabalho como princípio educativo, desenvolvem-se no contexto capitalista. Conforme avaliaram Frigotto e Ciavatta (2011), a passagem do governo Fernando Henrique Cardoso para o governo Lula e Dilma conservou a estrutura e as relações de classes sociais, aspecto que não contribui para o encaminhamento e valorização da educação como herança social, que deveria ser disponibilizada a todos os cidadãos. Percebe-se, com base nos autores, que permanece uma visão que desvaloriza a profissionalização. $\mathrm{O}$ resultado tem sido o encaminhamento da educação profissional que conserva a dimensão econômica, um aspecto que, de acordo com a análise dos mesmos, implica ainda a necessidade de "renascer das cinzas" (FRIGOTTO; CIAVATTA, 2011, p. 633).

Essa questão nos remete ao rompimento com uma prática pedagógica que resulta numa formação que vinha sendo desenvolvida no ensino médio, embasada na pedagogia das competências, assunto que foi observado por Ramos (2005). Para a autora, a lógica seguida com a proposta de integração entre educação profissional e ensino médio parte de uma concepção de homem e de totalidade muito distante daquela que sustenta a pedagogia das competências. Ramos (2005, p. 114) define o "[...] homem como ser histórico-social", que age e transforma a natureza, transformando-se, porém, numa realidade considerada concreta, “[...] síntese de múltiplas determinações”. Essas concepções não combinam com as que orientam o encaminhamento da pedagogia das competências na visão da autora:

\footnotetext{
A pedagogia das competências apoia-se no pressuposto de que os saberes são construídos pela ação. A competência caracteriza-se pela mobilização de saberes, como recursos ou insumos, por meio de esquemas mentais adaptados e flexíveis, tais como análises, síntese, inferências, generalizações, analogias, associações, transferências, entre outros. Por essa perspectiva, a finalidade da prática pedagógica seria propiciar a mobilização contínua e contextualizada dos saberes, sendo os conteúdos disciplinares insumos para o desenvolvimento de competências. Por isso o currículo passa a ser orientado pelas competências que se pretende desenvolver, e não pelos conteúdos a se ensinar" (RAMOS, 2005, p. 117).
} 
Entende-se que fatos como a proposta de implementação da integração da educação profissional ao ensino médio, a revogação do Decreto 2.208/97, assim como a mudança de governo federal ou estadual, por si só não eliminam o encaminhamento de práticas pedagógicas que se desenvolveram com o intuito de valorizar competências, de promover um vínculo com o mercado do trabalho e de assumir propostas de curso solicitadas por seus representantes que, de alguma maneira, contribuíam para a definição de propostas de curso.

Observa-se que a integração da educação profissional ao ensino médio, no Paraná, segue em caminho inverso às orientações das Diretrizes Curriculares Nacionais para o Ensino Médio (BRASIL, 1998) e das Diretrizes Curriculares Nacionais para a Educação Profissional Técnica (BRASIL, 1999), que, conforme comentaram Saldanha e Oliveira (2012), foram mantidas separadas sem que se consolidasse a integração.

A segunda questão vincula-se à primeira questão e relaciona-se à implementação da proposta nas escolas. Mesmo com todo o esforço, a disseminação da reestruturação curricular fica obstaculizada por aspectos como tempo dos professores que participam dos seminários de reestruturação e tempo escolar para estudo e implementação. Além disso, há a necessidade de compreender os fundamentos da reestruturação curricular, elemento que consideramos requerer muito estudo por parte daqueles que vão trabalhar nas escolas, seja na elaboração das propostas de curso, seja na implementação das mesmas.

A concepção de formação pretendida na proposta de integração, objeto da reestruturação curricular no Paraná no período em análise, também se depara, em nosso entendimento, com o obstáculo de ter início no nível médio e profissional, sem que se processe a necessária integração com o ensino fundamental. Percebe-se haver um fosso entre o ensino fundamental e o médio em que as propostas para formação apresentam-se duais, desintegradas, embora os professores da base comum sejam docentes que atuam nos anos finais do ensino fundamental.

Ressalta-se, ainda, que o conhecimento adquirido nesse espaço é primordial para o encaminhamento do trabalho de profissionalização que se pretende no médio e que, cumpre lembrar a partir das reflexões de Saviani (2007), a importância de tais conhecimentos da escola elementar, já que seria difícil pensar o conhecimento científico que respalda um saber profissional sem retomar o conhecimento adquirido em etapas anteriores e sem estabelecer relação com ele. Para nós, tal base deve ser objeto de reflexão.

Esse dado é reforçado em pesquisa desenvolvida por Griebeler (2013, p.169), ao comentar sobre a ausência de um quadro docente efetivo e a forma como os cursos são organizados a partir de disciplinas e conteúdos, e que, segundo a autora, “[...] o que vem ocorrendo é uma junção, uma articulação dos conhecimentos e conteúdos de forma fragmentada, $[\ldots]$... A presença de um quadro docente efetivo agrava-se, considerando, como mencionaram Saldanha e Oliveira (2012, p. 52), que ocorreu contratação “[...] constante durante os anos de 2003-2010 de profissionais temporários, através de processo seletivo simplificado (PSS)". A análise das autoras permite avaliar que esse foi um aspecto que 
comprometeu a implantação da proposta de integração no Estado do Paraná, já que, havendo contratação constante, ocorreria a rotatividade docente, e um incessante reinício da integração a partir da compreensão e ação dos docentes que estavam se inserindo na rede de ensino.

Observamos que as dificuldades encontradas nesse percurso explicitam divisões e antagonismos que estão na base da organização da sociedade capitalista e não deixamos de reconhecer, por isso, o esforço daqueles que se envolveram no encaminhamento da integração entre educação profissional e ensino médio. No entanto comentamos esses aspectos a fim de reiterar a complexidade de tal ação que se depara com obstáculos que, por vezes, se apresentam maiores que o desejo de mudar os rumos da educação.

\section{Algumas Considerações}

A análise realizada até o momento nos permite deduzir que as ideias, estratégias e políticas voltadas para a profissionalização de jovens brasileiros foram direcionadas a atender à necessidade de formação de mão de obra para o mercado de trabalho. No contexto recente, a formação, no que se refere à sua organização, tem atendido cada vez mais aos reclames neoliberais que se apresentam sob forma de manobras salariais, formação de mão de obra de reserva, responsabilização do trabalhador pelo desemprego e estímulo à empregabilidade. Desconsideram-se, nesse processo, as dificuldades que resultam do desemprego estrutural, cuja origem está no desenvolvimento tecnológico e na especulação financeira.

Esses aspectos que caracterizam a contemporaneidade são reforçados pela conformação social em virtude das alterações do Aparelho do Estado, que levam os indivíduos a naturalizarem o papel do poder público em relação à profissionalização. Disso decorrem a privatização da formação e a substituição da qualificação pela certificação, aspectos visíveis na valorização da pedagogia das competências.

Algumas perdas podem ser contabilizadas nesse processo. Se, nos tempos fordistas, a ampliação da qualificação e o exercício de atividades daí decorrentes eram revertidos em ganhos salariais, hoje, em tempos de acumulação flexível, a valorização da certificação em quantidade apenas legitima a perda de direitos, o rebaixamento salarial e a intensificação do trabalho. Desse processo, resta o incentivo às atividades do trabalhador que irá gerenciar o seu futuro com ações empreendedoras, destino perseguido também pela formação que pretende capacitar o profissional para sua autonomia.

Outra questão a ser lembrada é o descompasso entre o desenvolvimento tecnológico e produtivo e a formação profissional encaminhada através das legislações destacadas. A discrepância das propostas que fragmentam a formação e visam ao adestramento não combina com as necessidades de uma formação que permita o acompanhamento do sistema produtivo em veloz desenvolvimento.

O último aspecto não se dá apenas pelas questões internas do país, mas também pela sua condição de país menos desenvolvido que acata as sugestões de representantes de países 
desenvolvidos no direcionamento da educação e da formação profissional. A situação de dependência e de descaso com a formação nos faz pensar que projeto de nação queremos e nele nos empenharmos, caso contrário seremos um "país gigante de pés de barro" (FRIGOTTO; CIAVATTA; RAMOS, 2005, p.1) ${ }^{3}$.

Esses dados nos levam a refletir sobre a formação profissional como uma questão imprescindível a um país que busca o desenvolvimento, mas que tem, outrossim, o dever de pensar na melhoria das condições de vida dos trabalhadores garantindo-se-lhes a formação profissional como direito social.

\section{Referências}

ANGELI, R.F. O Ensino Médio Integrado à Educação Profissional no Paraná: a experiência de reconstrução da integração da formação geral e profissional. In: PARANÁ. Secretaria de Estado da Educação. Superintendência da Educação. Departamento de Educação e Trabalho. O Ensino Médio Integrado à Educação Profissional: concepções e construções a partir da implantação na Rede Pública Estadual do Paraná. Curitiba: SEED, 2008.

BRASIL. Decreto N. 5154, de 23 de julho de 2004. Regulamenta o $§$ do art. 36 e os arts. 39 a 41 da Lei n. 9.394, de 20 de dezembro de 1996, que estabelece as diretrizes e bases da educação nacional, e dá outras providências. Disponível em:

<http://www.planalto.gov.br/ccivil_03/_ato2004-2006/2004/decreto/d5154.htm>. Acesso em 9 jul. 2012.

BRASIL. Casa Civil. Lei 9.394, de 20 de dezembro de 1996. Lei de Diretrizes e Bases da Educação Nacional. Disponível em:

<http://www.planalto.gov.br/ccivil_03/LEIS/L9394.htm>. Acesso em: 16 ago. 2015

BRASIL. Casa Civil. Decreto n. 2.208, de 17 de abril de 1997. Regulamenta o $§ 2^{\circ}$ do art. 36 e os arts. 39 a 42 da Lei $n^{\circ}$ 9.394, de 20 de dezembro de 1996, que estabelece as diretrizes e bases da educação nacional. Disponível em:

<http://www.planalto.gov.br/ccivil_03/decreto/D2208.htm>. Acesso em: 22 ago. 2015.

BRASIL. Ministério da Educação. Parecer CNE/CEB N. 15/1998, de 1 de junho de 1998. Institui as Diretrizes Curriculares Nacionais para o Ensino Médio. Disponível em: <http://portal.mec.gov.br/cne/arquivos/pdf/1998/pceb015_98.pdf>. Acesso em: 22 ago. 2015.

BRASIL. Ministério da Educação. Parecer CNE/CEB N. 16/99, de 05 de outubro de 1999. Institui as Diretrizes Curriculares Nacionais para a Educação Profissional de Nível Técnico.

\footnotetext{
${ }^{3}$ Os autores usaram essa expressão para afirmar a necessidade de uma formação profissional como direito social.
} 
Disponível em: <http://portal.mec.gov.br/cne/arquivos/pdf/1999/pceb016_99.pdf>. Acesso em: 22 ago. 2015.

FERREIRA, E.B.; GARCIA, S.R. O. O ensino médio integrado à educação profissional: um projeto em construção nos estados do Espírito Santo e do Paraná. In: FRIGOTTO, G.; CIAVATTA, M.; RAMOS, M. (Orgs). Ensino Médio Integrado: concepção e contradições. São Paulo: Cortez, 2005. p. 148-173.

FRIGOTTO, G.; CIAVATTA, M.; RAMOS, M. A Gênese do Decreto N. 5154/2004. Um debate no contexto controverso da democracia restrita. In: FRIGOTTO, G.; CIAVATTA, M.; RAMOS, M. (Orgs). Ensino Médio Integrado: concepção e contradições. São Paulo: Cortez, 2005. p. 21-56.

FRIGOTTO, G.; CIAVATTA, M. Perspectivas sociais e políticas da formação de nível médio: avanços e entraves nas suas modalidades. Educ. Soc., Campinas, v. 32, n. 116, p. 619638, Jul./Set. 2011. Disponível em: <http://www.cedes.unicamp.br>. Acesso em 20/05/2014.

GRIEBELER, J.R.C. A política de Educação Profissional articulada ao Ensino Médio na forma integrada no Paraná: uma análise da implementação no Colégio Estadual João Manoel Mondrone no Município de Medianeira - Paraná (2003-2010). 2013. 198 f. Dissertação (Mestrado em Educação) - Universidade Estadual do Oeste do Paraná, Cascavel, 2013.

HARVEY, D. Condição Pós-moderna: uma pesquisa sobre as origens da mudança cultural. São Paulo: Loyola, 1994.

MACHADO, L.R.S. Politecnia, Escola Unitária e Trabalho. São Paulo: Cortez, Autores Associados, 1989.

MACHADO, Lu L.R.S. Politecnia no Ensino de Segundo Grau. In: GARCIA, W.; CUNHA, C. (Coords.). Politecnia no Ensino Médio. São Paulo: Cortez; Brasília: SENEB, 1991. p. 5164. (Cadernos Seneb, 5).

MANACORDA, M.A. Marx e a Pedagogia Moderna. São Paulo: Cortez: Autores Associados, 1991.

MANFREDI, S.M. Educação Profissional no Brasil. São Paulo: Cortez, 2002.

MARX, K.; ENGELS, F. Textos sobre Educação e Ensino. São Paulo: Centauro, 2004.

PARANÁ. Secretaria de Estado de Educação. Superintendência da Educação. Departamento de Educação Profissional. Fundamentos Políticos e Pedagógicos da Educação Profissional do Paraná. Curitiba: SEED, 2005. 
RAMOS, M. Possibilidades e Desafios na Organização do Currículo Integrado. In: FRIGOTTO, G.; CIAVATTA, M.; RAMOS, M. (Orgs). Ensino Médio Integrado: concepção e contradições. São Paulo: Cortez, 2005. p. 106-127.

RAMOS, M. Concepção do ensino médio integrado [Online]. In: Portal do IIEP Intercâmbio, Informações, Estudos e Pesquisas. 2008. Disponível em:

<http://www.iiep.org.br/curriculo_integrado.pdf> Acesso em: 10 jun. 2013.

SALDANHA, L. de L. W.; OLIVEIRA, R.C.S. Avanços e contradições da política de Educação Profissional Integrada no Paraná (2003-2010). Jornal de Políticas Educacionais, Curitiba, v.6. n.11, p. 45-56, Jan./Jun. 2012.

SAVIANI, D. A Nova Lei da Educação: trajetória, limites e perspectivas. Campinas: Autores Associados, 1997.

SAVIANI, D. Trabalho e Educação: Fundamentos Ontológicos e Históricos. Revista Brasileira de Educação, Campinas, v.12. n. 34. p. 152-180, Jan./Abr. 2007

Recebido em: 12/06/2013

Revisado em: 23/09/2014

Aprovado para publicação em: 31/03/2015

Publicado em: 31/08/2015 